\title{
Quality Assurance Concepts of Institutionalization: Some Indicators towards Higher Educational Development Policy in Libya
}

\author{
Milad EL Harathi \\ Benghazi University, Libya
}

\begin{abstract}
The aim of this paper is to lay down some indicators for establishing new Libyan national development policy in the higher education sector, after the political changes in Libya in 17-2-2011 uprising and demolishing the old mechanism of controlling the higher education system in Libya. Its attempt shall be based on rediscover ways of achieving quality and sustaining it in the Libyan higher education system. This therefore, is the task of this paper. It will examine the concept of quality assurance and apply it to a Libyan University Institute.
\end{abstract}

Keywords: University mission, student policy, education, national development

\section{Introduction}

The University Mission: The strategic position of the university in any national development policy is beyond doubt. The original mission of any given university is primarily to promote knowledge through research and teaching. It is also to explore solutions to the country's problems and assist the larger society to achieve its objectives in the areas of human social and economic development as following:

- Contribute to national development through high-level relevant labor training.

- Develop and inculcate proper values for the survival of the individual and society.

- Develop the intellectual capability of individuals to understand their local and external Environments.

- Acquire both physical and intellectual skills, which will enable individuals to be self reliant and Useful members of the society.

- Promote and encourage scholarship and community service.

- Promote national and international interaction

The University Objectives: These goals will pursue through teaching, research, virile staff development programmes, generation and dissemination of knowledge. The policy expects the Libyan universities specifically to make optimum contribution to national development by intensifying and diversifying their programs for the development of high level manpower within the context of the needs of the new Libyan society`. The professional course contents of university education should also reflect national requirements and Libya's society needs of knowledge. The policy also provides that university research will be relevant to new Libya's development goals and needs. It is evident from these policy expectations that the university institution should be the basic think tank of the Libyan society in all areas. It should continuously generate ideals and knowledge and disseminate them, develop skills and abilities in all who seek knowledge within its walls. The university institution in new Libya should be the vanguard of societal responses to emergent political, economic, social and environmental problems. The advancement of humankind through the ages has been knowledge driven and knowledge is the basic product of universities. For the Libyan education higher institutions to fulfil its mission, in general, it must devise ways of reversing the downward spiral in the quality of knowledge at produces and the services its delivers to its stakeholders and society. It must rediscover ways of achieving quality and sustaining it. This therefore, is the task of this paper. It will examine the concept of quality assurance and apply it to the Libyan education higher institutions production function in general. For instance, why should the education institution in Libya assures of its products and services, its inputs and its outputs? What strategies can Libyan education higher institutions adopt with regard to these elements to assure quality? These questions shall be addressed in this paper through an educational quality Assurance thoughts and indicators, and how it can institutionalized in Libya? 
Quality Assurance Concept: Quality assurance is a holistic term, which directed toward education as an entity. It entails the supplier and consumer and the various activities put in place to produce quality products and services. To further examine this concept meaningfully, three approaches to the definition of quality will be used. These are "the reputational approach, the outcomes approach and the total quality approach".

- The Reputational Approach: This approach sees quality as exceptional, it is seen as exclusive. It is something that "some have at the exclusion of others". It is distinctive and intuitively recognizable. This approach regards quality as excellence, it is a standard attained in our context by exceptional universities and or their products.

- The Outcomes Approach: This regards quality as efficient production. Here, there are no absolute standards but specifications. The quality of a product is measured by the extent to which it meets customer's specifications. This approach is more related to practices in industry.

- Total Quality Approach: Here quality is seen as value added. How much value has been added to the abilities of students for instance, who have passed through the system regardless of their ability levels? These are different views of quality when put together. However, we can accept that quality with regard to the output of university education is 'the level of excellence in performance on the strength of the quality of the context, inputs, process transaction and output"... This shows that to attain or assure quality in output a lot quality inputs and processes would have made. Quality in output does not come by chance. It requires carefully planned and deliberate efforts.

\section{Meaning of Quality Assurance}

The general meaning of quality assurance is very applicable to the production function of universities. It is the management of goods, services and activities from the input stage, through processes, to the output stage of production, Quality assurance aims at preventing quality problems and ensuring that only conforming products reach the customer. The characteristics of an effective quality assurance mechanism are an effective quality management system Periodic audit of the operation of the system, Periodic review of the system to ensure it meets changing requirements. It is clear therefore that an assurance process recognizes the need for a university to accept responsibility for its own management processes. This is the difference between quality assurance and inspection or evaluation. Quality assurance is a total, holistic process concerned with ensuring the integrity of outcomes. This places the responsibility for quality with the factory (university) itself, and thus expressed through its relationship with its customers. Quality assurance recognizes the autonomy of organizations and seeks to enhance their capacity to operate in a responsive way. We can see here that individual universities have a responsibility of assuring the quality of their product and that is why our focus here is on quality assurance mechanism of the Libyan University Institution, in general.

Quality in Higher Education Meaning: According to the author, it is possible to identify at least five definitions (Harvey and Green, 1993). First, is to see it as "producing perfection through continuous improvement by adopting Total Quality Management (TQM) to create a philosophy about work, people and human relationship built around shared values". This is a definition that points to the ideal, against which all other achievements are measured. The second and less formidable definition is to see quality as" performance that is exceptional, attainable only limited circumstances and only when very able students are admitted ". The third is to see it as the "ability to transform students on an on-going basis and add value to their knowledge and personal development". The fourth definition is to see it as" the ability to provide value for money and to be publicly accountable ". The fifth definition sees "quality as something which fits the purpose of the product or service, once the purpose has been decided" (Bogue and Saunders, 1992).

Quality Assurance Requirements: The experiences of the most developed countries suggest that the adoption of an instrumental approach to quality assurance in higher education can only work if a number of conditions are met. The first condition is that academic staff members are qualified. Research and teaching up to an acceptable level and the valuable nexus between them can only be produced two three when basic knowledge of the subject and the methodologies for research and teaching is present. Without this, research will be poorly formulated and executed, teaching lacking in breadth, depth and effectiveness, and the 
introduction of quality assurance not do much to increase standards to the desired level. The second condition is that academics need only to be employed in one full-time job in one institution to live comfortably with their families. They can earn extra income by doing short-term consultancy work for industry, government or international organizations as part of their direct community service function. The third condition is the presence of adequate physical, electronic and administrative support services, such as well equal.

\section{Indicators of Quality in Higher Education}

There are indicators that are associated with quality education: These indicators are crucial to quality. They include:

- The students: In industry, product quality to a certain extent depends on the quality of raw materials input. Quality leather, all other variables being favourable would invariably lead to quality shoes. Quality grapes to quality drink. In university education, the quality of student input is crucial to their eventual outcome what knowledge and abilities do they already possess? Some assumptions are made regarding those when students are admitted to universities. We assume they had learned what they were supposed to learn at the lower levels of educational structure. If they did not and somehow cheated their way into the universities, the deficiencies will persist and eventually manifest in them as low quality products. The university does not perform miracles. If the society offers defective raw materials, it can only at best ameliorate the effects at the output end of the processes. To assure quality in student output by the universities, the primary and secondary levels of the system must also ensure quality in their productivity.

- University Professors: The public policy on higher Education recognizes that no education system may rise above the quality of its teachers). The quality of lectures in the universities determines largely, the quality of those that they produce and the quality of their research output. In the fifty years of the development of university education in Libya, there was a lack of orderly and prosperous growth, especially during the "People's Committee Rule of the education sector in Libya. The lecturers in the universities at the time were less world class. They had not integrity both personal and intellectual. The system was always not improving them through training and retraining in the best universities in the world.

- Context: If the university has well, quality learners and professors but run irrelevant programmes that do not relate to the needs of the society nor with the "specifications" of the stakeholders and consumers, and then does quality in this context suffer. The national policy on education enjoins the universities to design course content that will reflect our national requirements. It there is a continuing mismatch between what is offered in the universities and what society needs, then regardless of the nature of what is offered, it would still in this quality context be of poor quality. Context here must also be aligned with adequate and appropriate materials, and equipment for teaching and learning. Workshops, laboratories, libraries and modern technology like ICT go as required with the context.

- Teaching: Teaching is separated here from teachers as a quality indicator because not much teaching goes on in the universities even with highly qualified academic staff in the department. Quality teaching involves not only possession of knowledge but also the ability to transfer knowledge, skills and attitudes to the learners. This is why the Educational public Policy envisages that all teachers in our educational institutions shall be required to undergo training in the methods and techniques of teaching these calls for training in methods and techniques in teaching.

- Teaching/Learning Environment: Good learning environment promotes quality higher education. Environment here goes beyond the physical structures and beautiful aesthetic landscaping. Important though these are to quality learning, it includes adequate policies and practices, which prohibit students and teacher harassment, examination malpractice, cultism and attendant violence. It connotes good academic culture. At the early stages of University development in Libya there was 
adequate classrooms, offices hostel accommodation for students, large auditoriums for universities wide activities. The campuses were student friendly. With the radical increase in student enrolment that were not matched with corresponding improvement in facilities and funding, the existing facilities were over-stretched and ill maintained. They can no longer support the programmes of the universities leading to improvisation that have affected quality:

- Measurement and Evaluation: Quality must be measurable and clearly defined. In other words, there should be clearly defined learning outcomes such as knowledge, attitudes and skills expected of anyone who has gone through any course of study in the university. There must be suitable ways of assessing these at university and national levels. From our discussion of indicator of quality education, we can identity possible assurance mechanism in the university. These are

- Students admission policy

- Recruitment and selection policy of academic staff

- Circular policy (academic programmes)

$\circ$ Supervision of instruction and teaching effectiveness.

- We here discuss how these mechanisms can be put in place if they are not already being used and or strengthened if they are:

- Student Admission policy: Students are the raw materials that are taken into the university, processed and turned out on graduation as finished products to employers and society as customers. Admission standards in excellent universities are very high indeed. Only the finest candidates meet the requirements. The position of this presentation is that this move be strengthened to recover the autonomy of universities in determining their raw materials. Also that policy enrolment and admission to the university level requirements.

- Recruitment and Selection of Academic Staff: The universities have autonomy in this regard. They recruit and select their staff. The only limitation here is that they cannot fix their remuneration outside the authority approved structure which unfortunately cannot attract desired teaching personnel from anywhere in the world. Even at the present level of enhancement, the remuneration package of the Libyan university teacher is still lower than the average in the Arab world and this becomes an impediment to attracting lectures in relevant areas from some Arab countries, Europe, America, Japan and other key Asian countries. The concept of the university requires that its academic staff disposition is universal in profile. That is why some culture specific programmes like foreign languages and high technologies, modern studies, Institutions of American and European Studies etc should for purposes of universal relevance and comparison have on their teaching staff, specialists from those cultures. Since quality has to do with relevance this obviously has a quality assurance implication.

- Circular policy: This is a quality context. Quality assurance in the university must have to do with the relevance of the programmes. There must be societal justification for every programmed on the curriculum. It must be social, economic, political, cultural, environmental or some or all of these. This sees quality as relevance. It must have utility. It must not be an abstraction. Any Libyan University in the following areas can assure these:

- Periodic review of existing programmes to check on flaws breakdowns. This can be done every two years or by one year.

- Review of objective in the light of changing needs and demands of the society.

- Ensure that the procedure for modifying programmes (deletion and addition of courses) is not

- Cumbersome. This way, outdated and irrelevant courses are quickly removed and new ones added.

- Supervision of Instruction and Teaching Effectiveness: The quality of teaching has considerably declined in the Libyan universities. This may well be the reason why the National Policy on higher 
Education provides that all teachers in our national institutions shall be required of undergo training in the methods and techniques of teaching. Possession of knowledge is one thing; ability to transfer it to others is another. That is why university professor is discipline and teaching a profession. In his inaugural lecture on the improvement of instruction and teacher effectiveness in our higher educational institutions, recommended among other things that student ratings of lecturers teaching at the end of courses) should be augmented by other approaches in making promotion decision on lecturers. That is why one cannot publish at the expanse of teaching and expect a favourable appraisal. They should complement each other.

\section{Conclusion}

This presentation have examined the necessity for quality assurance institutionalization in the Libyan university institution, and provided her as an indicators and concepts presented to the new public policy makers in new Libya. The indicators of quality, the production function of the university and the strategies universities can adopt, in the Libyan education system, to assure quality of their products. It has becomes clear that universities have heavy responsibility in this regard. A task must be done because a system that does not assure quality of its products in a global market that is competitive will eventually become unsustainable. We must however realize that many if not all the strategies discussed here have funding implications. Those whose responsibility it is to fund universities should take those it is to manage these funds should take even more note actions so that the university institution in new Libya can truly begin to fulfil its mission.

\section{References}

Benghazi University, the yearly Book Report. (2005). (Arabic Text).

Benghazi University, the Yearly Book Report. (2007). (Arabic Text).

Bogue, E. \& Saunders, R. (1992). The Evidence for Quality. San Francisco: Jossey-Bass.

Harvey, L. \& Green, D. (1993). Defining quality, Assessment and Evaluation in Higher Education. An International Journal, 18(1).

Ministry of Education, Annual Academic Report. (2008).

Quality Assurance Center, Ministry of Education Report, Tripoli. (2010).

Round Table of Quality Assurance in Gharyounis University. (2010). Sponsored by UNESCO, Beirut Office, Benghazi, 28-5 to 30-5-2010.

Martin Carny (1999). Globalization Education Reform, UNESCO, Paris, 1999.

Education (2006). Higher Education and Scientific research in Muslim Countries: Status and future prospects (paper in English), UNESCO, 2006. 